\title{
O Ensino de Arte e a EJA nos Documentos da Educação Básica em Tocantins: Desafios para a Formação Docente
}

\section{Art Teaching and Youth and Adult Education in basic education Documents in Tocantins: Challenges for Teacher Training}

\author{
Luis Gomes de Oliveira*a; Rosane Gomes de Araújo ; Gustavo Cunha de Araújo ${ }^{\mathrm{a}}$
}

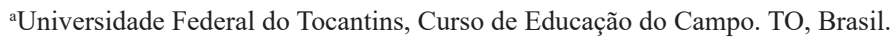

*E-mail: luisgomesoli@gmail.com

\begin{abstract}
Resumo
A história da democratização da educação traz consigo uma luta da classe trabalhadora de jovens e adultos, para que a educação seja mais acessível e gratuita a todos. Assim, com a Constituição Federal de 1988, o direito à igualdade, à educação e à universalização do ensino influenciaram a criação de políticas públicas voltadas ao desenvolvimento do ensino na educação brasileira. O artigo apresenta como objetivo compreender como a Arte e a EJA são concebidas nos documentos oficiais da Educação Básica e da Educação de Jovens e Adultos (EJA) no Estado do Tocantins. Esta pesquisa segue a abordagem qualitativa, de caráter descritivo e de natureza documental. A disciplina de Arte não está bem delineada nos anos da Educação Básica deste Estado, uma vez que, embora os documentos analisados afirmem da importância dessa área para a produção de conhecimento, não deixam claro se essa disciplina ocorrerá em todo o Ensino Fundamental, Ensino Médio e na EJA. É possível afirmar, portanto, que os jovens e os adultos vão à escola não por obrigação, mas porque eles têm interesse e necessidade de aprender. Por isso, que deve ser considerado nos processos pedagógicos em artes desenvolvidos com eles, assim como nos documentos/legislações que regem a Educação Básica no Estado do Tocantins os seus saberes e experiências construídos ao longo de suas vidas.
\end{abstract}

Palavras-chave: Arte. Educação de Jovens e Adultos. Educação Básica. Tocantins.

\begin{abstract}
The history of the democratization of education brings with it a struggle by the working class of young and adults people to make education more accessible and free to all. Thus, with the 1988 Federal Constitution, the right to equality, to education, and the universalization of education influenced the public policies creation aimed at the development of teaching in Brazilian education. Its main objective is to understand how Art and Youth and Adult Education (YAE) are conceived in the official documents of Basic Education and YAE in the State of Tocantins, Brazil. This research follows the qualitative, descriptive and documental approach. The subject of Art is not well delineated in the years of Basic Education of this state, since, although the documents analyzed confirm the importance of this area for the knowledge production, they do not make clear if this subject will occur in the entire Elementary and High School Education, including in institutions that have YAE. It is possible to say, therefore, that young people and adults go to school not out of obligation, but because they have an interest and need to learn. That is why their knowledge and experiences built throughout their lives must be considered in the pedagogical processes in arts developed with them, as well as in the documents/legislations that govern basic education in the state of Tocantins.
\end{abstract}

Keywords: Art. Youth and Adult Education. Basic Education. Tocantins.

\section{Introdução}

A história da democratização da educação traz consigo uma luta da classe trabalhadora de jovens e adultos, para que a educação seja mais acessível e gratuita a todos. Assim, com a Constituição Federal de 1988, o direito à igualdade, à educação e à universalização do ensino influenciaram a criação de políticas públicas voltadas ao desenvolvimento do ensino na educação brasileira.

Embora a EJA tenha conquistado vitórias importantes na educação no que se refere à legislação, nota-se que há muito que se fazer no que diz respeito no aumento da qualificação na área dos educadores que atuam nessa modalidade (DI PIERRO, 2005). Especificamente, na disciplina de Arte na EJA, quase a totalidade de escolas públicas localizadas na região Norte do Estado do Tocantins, local deste estudo, não possui professores formados em artes para atuarem nessa disciplina (ARAÚJO; OLIVEIRA; ALMEIDA, 2019), o que se mostra preocupante no que concerne a carência de formação e qualificação do professor que atua na área nos diferentes segmentos da Educação Básica e na EJA.

$\mathrm{O}$ artigo é fruto de uma pesquisa financiada pela Universidade Federal do Tocantins, referente às bolsas de Iniciação Científica (PIBIC) e faz parte de um projeto de pesquisa mais amplo em desenvolvimento nessa Instituição, campus de Tocantinópolis, intitulado "Ensino desenvolvimental e histórias em quadrinhos: implicações da teoria Histórico-Cultural para a formação integral do estudante jovem e adulto". Especificamente, para este artigo, trata de socializar resultados parciais da pesquisa de PIBIC.

Apresenta como objetivo principal compreender como 
a Arte e a EJA são concebidas nos documentos oficiais da Educação Básica no Estado do Tocantins, a partir de uma pesquisa de abordagem qualitativa, de caráter descritivo e de natureza documental.

Ao situar este estudo no contexto da Educação de Jovens e Adultos, a partir de uma pesquisa realizada na região Norte do país, tenta-se complementar outros estudos que abordam esse tema em diferentes contextos brasileiros, contribuindo de maneira mais ampla para a produção de conhecimento na área. Com efeito, o estudo pode fornecer informações valiosas sobre o ensino de arte na EJA, importante para a produção de conhecimento na área.

A partir dessas primeiras considerações, o artigo está estruturado da seguinte forma: primeiramente, são apresentados os procedimentos metodológicos da pesquisa, buscando revelar como a pesquisa foi pensada, planejada e executada. Em seguida, socializam-se uma síntese da revisão bibliográfica realizada acerca da EJA e Arte, para que as reflexões produzidas neste texto pudessem ser problematizadas. Os dados gerados na pesquisa são discutidos em seguida, à luz da matriz teórica que fundamenta esta investigação. Por fim, são apresentadas algumas conclusões parciais desta pesquisa.

\section{Desenvolvimento}

\subsection{Metodologia}

Esta pesquisa segue a abordagem qualitativa, de cunho bibliográfico e de natureza descritiva e documental. Essa abordagem de pesquisa, bem como o seu caráter e natureza permitem estabelecer uma compreensão mais esclarecedora do objeto de estudo (BOGDAN; BIKLEN, 1994). A forma de análise dos dados seguiu a técnica da pesquisa interpretativa (ERICKSON, 1985).

Os dados foram gerados a partir da pesquisa em artigos, livros e documentos referentes às artes, EJA e legislação em Tocantins, no formato on-line e impresso. Após esse levantamento, foram sistematizadas, categorizadas e analisadas, segundo a perspectiva da pesquisa interpretativa e a base teórica utilizada nesta investigação. É importante destacar que a pesquisa de levantamento realizada é utilizada em estudos exploratórios e descritivos, com o objetivo de auxiliar o pesquisador a conhecer informações a respeito da realidade analisada (FONSECA, 2002). Portanto, entendese que esses procedimentos metodológicos adotados foram adequados aos objetivos deste estudo.

\subsection{Educação de Jovens e Adultos e o ensino de arte na pesquisa educacional}

Longe de revisar a história da Educação de Jovens e Adultos (EJA), não cabem nas reflexões desenvolvidas neste artigo repetições a respeito da historicização dessa modalidade na educação brasileira, mas propor algumas reflexões a respeito desta modalidade e artes, com o objetivo de problematizar a discussão proposta neste artigo.

Segundo Machado (1996), a Educação de Jovens e Adultos (EJA) não se limita apenas a escolarização, pois tanto na realidade brasileira quanto latino-americana sua história é marcada por lutas aos direitos, como o acesso e permanência a uma educação de qualidade, assim como direito à saúde, trabalho e moradia digna, seja no campo ou na cidade.

A esse respeito, é interessante frisar que:

[...] A sua importância nasce do caráter contraditório que a acompanha: nela sempre reside uma dimensão de luta. Luta por inscrições mais democráticas, por efetivações mais realistas, contra descaracterizações mutiladoras, por sonhos de justiça. Todo o avanço da educação escolar além do ensino primário foi fruto de lutas conduzidas por uma concepção democrática da sociedade em que se postula ou a igualdade de oportunidades ou mesmo a igualdade de condições sociais [...] Em todo o caso, a ligação entre o direito à educação escolar e a democracia terá a legislação como um de seus suportes e invocará o Estado como provedor desse bem, seja para garantir a igualdade de oportunidades, seja para, uma vez mantido esse objetivo, intervir no domínio das desigualdades, que nascem do conflito da distribuição capitalista da riqueza, e progressivamente reduzir as desigualdades (CURY, 2002, p. 247-249).

A citação é atual e pertinente, pois é importante garantir o direito à educação da população brasileira por meio de construções de políticas educacionais e, aquelas já existentes, que possam ser revisadas e reformuladas, para que o desenvolvimento do processo de ensino e aprendizagem do sujeito possa ocorrer de forma plena, sem deixar de lado os seus direitos de frequentar e permanecer na escola.

Dito com outras palavras, não basta apenas a Constituição Federal de 1988 assegurar o direito a uma Educação pública e gratuita para o cidadão, mas é necessário a criação de um Projeto Político-Pedagógico (PPP) nas escolas, que contemple a pluralidade cultural dos sujeitos jovens e adultos que trazem ricas experiências e saberes construídos ao longo de suas vidas. Educação é algo essencial para todo e qualquer ser humano ao longo de sua vida, o que implica em um engajamento maior do poder público para o seu pleno desenvolvimento. Com efeito, "este é o sentido de um projeto educador para Freire: não apenas ensinar a letra, mas levar o homem à consciência de si, do outro, da natureza" (PAIVA; HADDAD; SOARES, 2019, p.14). Por isso da importância de práticas docentes que dialoguem com as vivências de jovens e adultos na escola.

A partir do plano de normatização implementado pelo Estado para a modalidade supracitada, parece que se torna cada vez mais difícil a visibilidade dos sujeitos que precisam retornar à escola, pois as metodologias, o modo de avaliação, o currículo desconexo da realidade dos educandos e a falta de políticas públicas na formação de professores habilitados para atuarem na modalidade de ensino de jovens e adultos (EJA), ainda se mostram presentes nesse âmbito. Nesse aspecto:

[...] um dos elementos importantes para o sucesso das aprendizagens dos sujeitos da EJA depende das condições do exercício profissional docente, do trabalho com as demandas específicas de uma didática para EJA. Então, esse processo 
não requer qualquer mediação, mas sim uma mediação pedagógica crítica, fundamentada, planejada, intencional, em que professor (a) e aluno (a) são sujeitos de aprendizagem. (LAFFIN; RIBEIRO; SANCEVERINO, 2020, p. 17).

Por isso, é de fundamental importância garantir o direito à educação, através de construções de políticas educacionais e, aquelas já existentes, que possam ser revisadas e reformuladas, para que o desenvolvimento do processo de ensino e aprendizagem do sujeito possa ocorrer de forma plena, sem deixar de lado os seus direitos de ir e permanecer na escola.

Contudo, por mais que a EJA tenha conquistado importantes vitórias no decorrer de sua história, principalmente, no que diz respeito à legislação, ainda há uma carência significativa de investimentos nessa modalidade, o que pode ocasionar uma queda na qualidade do ensino ofertado para jovens e adultos, segundo literatura científica analisada nesta pesquisa. Além disso, a falta de professores de Arte que atuam nessa modalidade é outro agravante, pois, no caso específico deste estudo, constata-se que quase a maioria dos docentes que atuam nessa disciplina nas escolas pesquisadas localizadas na região da nossa pesquisa, não são formados em artes (artes visuais, teatro, dança ou música), o que revela a carência de formação docente inicial e continuada nessa área (ARAÚJO; OLIVEIRA; ALMEIDA, 2019).

$\mathrm{Na}$ esteira desse pensamento, de acordo com Lagares (2019), a precariedade do ensino no Estado do Tocantins, mais precisamente na região conhecida como bico do papagaio (região Norte e local desta pesquisa), como a falta de transporte, alimentação e condições dos estabelecimentos escolares, se mostra preocupante. Desse modo, a formação continuada dos professores e alunos ficou em segundo plano, pois parece que o poder público está mais preocupado em ampliar uma formação técnica integrada ao Ensino Médio, para que o aluno seja preparado diretamente para o mercado de trabalho, do que com a qualidade desse ensino ofertado nas escolas, e identificar se esse ensino alcança todos os estudantes das cidades e meio rural tocantinenses.

Nesse sentido, pensa-se que é de fundamental importância no processo educacional uma gestão democrática na formação dos sujeitos, sendo algo não isolado dos seus conhecimentos e necessidades, mas que seja organizado e pautado pela coletividade. Com essa afirmação, defende-se a ideia de que alunos e professores podem e devem fazer parte das decisões tomadas dentro da comunidade escolar. Assim:

[...] o modo como uma escola se organiza e se estrutura tem um caráter pedagógico, ou seja, depende de objetivos mais amplos sobre a relação da escola com a conservação ou a transformação social [...] concebem a participação de todos nas decisões como importante ingrediente para a criação e desenvolvimento das relações democráticas e solidárias (LIBÂNEO, 2001, p. 4).

Em consonância com esse fragmento de Libâneo, Lagares (2020) assevera que a gestão democrática está muito além de assinar papéis burocráticos, tomar decisões e mediar conflitos; é formação política, é compreender os sujeitos que fazem parte do ensino, sendo eles alunos e comunidade. Por isso da participação de todos na proposição e revisão de políticas públicas voltadas à educação, em geral.

No ciclo em discussão, é importante o professor ser um auxiliador para intermediar e apresentar aos alunos jovens e adultos possibilidades de se desenvolverem formas de conhecimento a respeito das artes. De fato, para que a assimilação do conteúdo por parte deles ocorra da melhor maneira, entende-se que seja necessário o professor sistematizar o que seus alunos entendem por arte e o que eles compreendem como arte, pois, assim, o educador terá uma ampla visão de como poderá trabalhar com os jovens e adultos, respeitando as suas especificidades e saberes.

Para encaminhar esse processo, criar questionamentos feitos pelo próprio educador, abordando assuntos sobre as manifestações culturais e artísticas da comunidade, bairro, município e até mesmo do Estado em que o discente vive, trabalha e se constitui enquanto sujeito histórico, pode motiválos a querer aprender temas referentes à sua realidade. Isso pode ajudá-lo a despertar a sua curiosidade na aprendizagem. Dessa forma, o professor poderá obter informações essenciais para planejar as suas aulas durante o semestre letivo (ARAÚJO; OLIVEIRA, 2015b).

Porém, para enriquecer esse processo de ensino e aprendizagem, menciona-se as artes, uma vez que se entende que o seu ensino é essencial para a formação humana, além de proporcionar ao educando fazer interpretações significativas do seu meio social e cultural, importante para a tomada de consciência da sua realidade. Sendo assim, se faz necessário a arte na EJA. Com efeito, com a arte, “[...] a escola tem sido um importante meio para a inclusão daqueles jovens e adultos que, por diversos e diferentes motivos, não puderam iniciar ou dar continuidade a seus estudos na educação básica" (ARAÚJO; OLIVEIRA, 2015, p.681).

\section{Resultados e Discussão}

\subsection{EJA e legislação educacional em Tocantins}

Como parte dos resultados encontrados nesta pesquisa se socializa neste artigo os estudos teóricos realizados acerca da EJA, artes e análises de alguns documentos educacionais voltados para um sistema educacional do Estado do Tocantins e no Brasil, para ajudar a ampliar um pouco mais a discussão proposta.

No desenvolvimento desta investigação, foram levantados e, posteriormente, analisados, os documentos constantes no Quadro 1, em consonância com as análises feitas por Oliveira e Araújo (2020) a respeito dessas legislações: 
Quadro 1 - Documentos a respeito da legislação sobre a EJA

\begin{tabular}{|c|c|}
\hline $\begin{array}{c}\text { Documentos a Respeito } \\
\text { da Educação Básica em } \\
\text { Tocantins }\end{array}$ & $\begin{array}{c}\text { Documentos a Respeito da } \\
\text { EJA }\end{array}$ \\
\hline $\begin{array}{l}\text { Estrutura Curricular para } \\
\text { os anos iniciais do Ensino } \\
\text { Fundamental (2016) }\end{array}$ & $\begin{array}{l}\text { Resolução CNE/CEB n. }{ }^{\circ} 1 \text {, de } \\
5 \text { de julho de } 2000 \text { (Estabelece } \\
\text { as Diretrizes Curriculares } \\
\text { Nacionais para a Educação de } \\
\text { Jovens e Adultos) }\end{array}$ \\
\hline $\begin{array}{l}\text { Estrutura Curricular para } \\
\text { os anos finais do Ensino } \\
\text { Fundamental (2016) }\end{array}$ & $\begin{array}{c}\text { Parecer CNE/CEB n. } .^{\circ} 11 \text { de } \\
\text { maio de } 2000 \text { (Estabelece } \\
\text { as Diretrizes Curriculares } \\
\text { Nacionais para a Educação de } \\
\text { Jovens e Adultos) }\end{array}$ \\
\hline $\begin{array}{l}\text { Estrutura Curricular da rede } \\
\text { Estadual de Ensino do Estado } \\
\text { do Tocantins (Resolução n. } \\
\text { 160, de } 19 \text { de dezembro de } \\
\text { 2016) }\end{array}$ & $\begin{array}{l}\text { Proposta Curricular Para a } \\
\text { Educação de Jovens e Adultos } \\
\text { (Segundo Segmento - Artes). } \\
\text { (2002) }\end{array}$ \\
\hline $\begin{array}{l}\text { Regimento Escolar da Rede } \\
\text { Estadual de Ensino do Estado } \\
\text { do Tocantins (2016) }\end{array}$ & - \\
\hline
\end{tabular}

Inicialmente, o "Regimento Escolar da Rede Estadual de Ensino do Tocantins" revela que a maioria dos jovens e adultos matriculados na rede pública de ensino do Estado cursa a $3^{\circ}$ série do Ensino Médio do $3^{\circ}$ seguimento da Educação de Jovens e Adultos, sendo predominante a quantidade de educandos nessa fase/etapa da modalidade em Tocantins, em comparação com os outros segmentos, segundo que conseguimos constatar nessa análise.

Por outro lado, o documento que organiza e estrutura a EJA na rede de ensino é a "Resolução no 160, de 19 de dezembro de 2016", voltada para as escolas estaduais tocantinenses. Esse documento assim se posiciona quanto a essa estrutura:

a. Educação de Jovens e Adultos indígenas para $1^{\circ}, 2^{\circ}$ e $3^{\circ}$ seguimentos;

b. EJA para $1^{\circ}, 2^{\circ}$ e $3^{\circ}$ seguimentos.

Pode-se observar um ponto interesse nesse documento: a presença da EJA com os jovens e adultos indígenas, o que é relevante e significativo para o Estado, uma vez que a presença de etnias como a Apinayé (pronuncia-se apinajé) entre outras, são muito presentes em diferentes localidades do Tocantins, principalmente, no Norte do Estado, região conhecida como "Bico do Papagaio". Nesse sentido, considerar esses educandos no processo de ensino e aprendizagem, bem como na estrutura curricular do Estado, é necessário para fortalecer a inclusão desses povos na educação escolar.

No que se refere à Arte, o documento "Regimento Escolar de Rede Estadual de Ensino do Tocantins" menciona que esse ensino é um componente curricular obrigatório da educação básica, que por vezes, pode abordar questões relacionadas à cultura de outros lugares e do país. $\mathrm{Na}$ análise feita neste documento, é possível identificar o ensino de arte como importante para trabalhar e estudar etnias do Estado, o que é importante, em função da diversidade cultural presente no Tocantins, o que é importante, pois o Estado do Tocantins. Por outro lado, chama-se atenção ao fato de que esses documentos, embora façam essa menção, não deixam evidente Arte é disciplina obrigatória em toda Educação Básica, o que vai ao encontro dos estudos de Barbosa (2012, 2010, 2008, 1998, 1990).

Seguindo essas reflexões, Barbosa (2017a, 2017b, 2017c) ressalta que a arte é importante na escola, porque desenvolve no indivíduo a capacidade crítica e intelectual, fundamental para o aprendizado de habilidades importantes em outras disciplinas, como, por exemplo, melhorar a escrita e leitura nas aulas de Língua Portuguesa, ou seja, lendo e compreendendo uma obra de arte, a partir da leitura visual, por exemplo, o estudante pode desenvolver a sua capacidade de leitura e interpretação de obras artísticas e visuais.

É essencial assinalar que não foram identificados nos documentos analisados aspectos da Abordagem Triangular de Ana Mae Barbosa (leitura, apreciação e produção artística), o que, nesta compreensão, deixa de aprofundar, tanto na teoria, quanto na prática, o conhecimento crítico de diferentes manifestações artísticas. Dito com outras palavras, essa abordagem é a proposta pedagógica em artes mais utilizada nas escolas brasileiras de Educação Básica, por considerar efetivamente na formação do aluno, a produção de conhecimento em arte (BARBOSA, 2012).

Em consonância com essas análises, em outro documento analisado, o Plano Estadual da Educação do Tocantins - PEE/ TO (2015-2025) mostra metas e estratégias para que ocorra a eliminação do analfabetismo no Brasil, de modo que não aconteça a desigualdade social educacional do sujeito através da EJA e que esse tenha direito à educação e permanência no ambiente escolar, sem exceção de cor, gênero, etnia entre outras classes sociais. Especificamente, a meta 7 dispõe que:

I - Promoção da educação escolar para jovens e adultos, com características e modalidades adequadas às necessidades e garantia das condições de acesso e permanência na escola; II - fortalecimento das articulações e o compromisso dos entes federados com a efetivação do ingresso, a permanência e a continuidade dos estudos de jovens e adultos; III - promoção da formação integral para o desenvolvimento das capacidades e competências adequadas, atendendo ao desenvolvimento sustentável e às novas transformações científicas e tecnológicas, numa perspectiva sócio-histórico/sociocultural (TOCANTINS, 2015, p. 13).

O fragmento acima é importante: o documento deixa claro que não é só dever do Estado, mas também do município a garantia de permanência dos sujeitos jovens e adultos na escola e na construção de políticas públicas para inclusão dos mesmos na sociedade.

Já o Documento Curricular do Tocantins Resolução $\mathrm{n}^{\circ}$ 024, de 14 de março de 2019, foi elaborado na perspectiva de entender a Arte como um instrumento de construção e transformação crítica dos sujeitos, a partir da interculturalidade existente em cada região, valorizando o fazer artístico dos sujeitos e que os mesmos podem ter contato com outras obras de artes nacionais e internacionais. Nesta análise, esse documento deixa evidente que os sujeitos ao terem contato 
com arte precisam desenvolver conhecimentos relacionados à criação, serem críticos e desenvolver a percepção visual e estética a partir do contato com uma obra artística, além de interpretarem o fazer artístico. Isso é importante para ajudar a compreender como a arte se manifesta na sociedade e, consequentemente, como contribui para a formação escolar dos educandos.

Essas análises nos conduzem a dizer que Arte é mais que uma disciplina. Ela abrange toda a grade curricular fazendo com que o aluno tenha uma nova visão de mundo e, consequentemente, que amplie o seu entendimento do que está a sua volta, coordenação motora e cognitiva, senso crítico e a capacidade de se expressar tanto na escrita quanto oralmente. Assim, na Educação de Jovens e Adultos, a arte pode ser ainda mais significativa para a aprendizagem desses educandos, ao proporcionar a eles, via produção artística, produzir interpretações significativas da realidade e a conhecer novas culturas (ARAÚJO; OLIVEIRA, 2015a).

Essas análises são importantes, pois ajudam a compreender que uma das formas de se trabalhar artes (área de conhecimento) ou Arte (disciplina curricular) com jovens e adultos é buscar trabalhar elementos que contemplem o conhecimento de vivência deles, tanto daqueles que vivem no campo quanto na cidade, como, por exemplo, o conhecimento estético, emocional, visão de mundo, leitura textual e visual, entre outros, pois a arte não é só desenho e pintura, tampouco apenas teoria; ao contrário, é conhecimento que permite compreender novas culturas e a promover uma fomentação mais crítica da realidade da qual faz parte o educando.

Nesse sentido, para que os alunos dessa modalidade possam entender e compreender a arte, primeiro é necessário que o professor busque elementos artísticos do sua região voltados para a realidade dos alunos, para que se possa iniciar a construção do conhecimento artístico e, assim gradativamente, proporcionar a eles o desenvolvimento da sensibilidade estética, da qual poderão ser capazes de questionar e analisar obras artísticas de forma crítica, relevante para compreender o mundo a sua volta e a tomarem consciência da realidade (ARAÚJO; OLIVEIRA, 2015b).

Com base nessas reflexões, para ser mediador de conhecimento entre alunos e artes, não basta apenas entender o que essa área significa, mas compreender seus aspectos, seus conceitos, suas transformações e como a arte pode interferir na vida daquele jovem e adulto que retorna para a escola para concluir os seus estudos. Por isso, da importância de compreender essas duas áreas (artes e EJA) na pesquisa educacional em Tocantins.

Para encaminhar as conclusões desta pesquisa, Pierro (2005) afirma que se faz necessário reconhecer essa modalidade como essencial para o ensino e aprendizagem desses indivíduos, visto que todos têm o direito à educação continuada e de qualidade com profissionais capacitados para atender esta demanda. Dito com outras palavras, a EJA não é apenas uma questão de fazer cumprir a legislação, mas uma obrigação do Estado para com todos os sujeitos que o constitui. Com efeito, o Estado deve propor políticas públicas adequadas e eficientes para o melhor desenvolvimento de ações voltadas à Educação de Jovens e Adultos, para que seja possível garantir o futuro de uma sociedade mais democrática, conscientizada e rica em igualdade social (HADDAD; DI PIERRO, 2000).

\section{Conclusão}

Evidenciou-se que a EJA deve valorizar a identidade e pluralidade dos indivíduos jovens e adultos, que veem nessa uma oportunidade de fazer valer seus direitos à educação, a tomarem consciência da realidade e se tornarem mais participativos em suas comunidades.

Em face da pesquisa bibliográfica realizada, identificase que as produções acadêmicas no campo da EJA com embasamento na aprendizagem em artes são carentes na literatura científica. Diante disso, entende-se que essa temática precisa melhor ser estudada e pesquisada, com o fito de ampliar a discussão acerca da qualidade de ensino ofertado aos jovens e adultos na educação escolar. No entanto, para isso, é preciso que a estrutura curricular das instituições que ofertam EJA e as práticas pedagógicas desenvolvidas nessa modalidade considerem as especificidades desses educandos, tanto relacionadas aos seus saberes, quanto aos conteúdos trabalhados em sala de aula.

Constata-se nas análises feitas nos documentos oficiais do Estado do Tocantins que a disciplina de Arte não está bem concebida nos anos/séries da Educação Básica desse Estado, uma vez que, embora esses documentos afirmem da importância dessa área para a produção de conhecimento humano (a consideram como área do saber), não deixam claro se essa disciplina (que eles chamam de "componente curricular") ocorrerá em todo o Ensino Fundamental e Ensino Médio, inclusive, em instituições que houver EJA, o que, neste entendimento, desvaloriza essa área como fundamental para a formação intelectual, cultural e artística do estudante.

Com efeito, espera-se que após a conclusão desta pesquisa, que se encontra em desenvolvimento, o estudo possa contribuir para pensar em estratégias pedagógicas e políticas públicas para a área de artes e EJA no Estado do Tocantins, ainda carente de cursos de formação inicial e continuada em artes.

A bagagem cultural dos jovens e adultos dessa modalidade de ensino que vivem a arte em suas comunidades por meio de suas culturas, tradições, artesanatos, danças e costumes é fundamental para que a disciplina de Arte considere em seu planejamento, bem como no Projeto Político Pedagógico (PPP) da escola, conteúdos próximos à realidade desses educandos.

É possível afirmar, portanto, que os jovens e os adultos vão à escola não por obrigação, mas porque eles têm interesse 
e necessidade de aprender. Por isso, que deve ser considerado nos processos pedagógicos em artes desenvolvidos com eles, assim como nos documentos/legislações que regem a Educação Básica no Estado do Tocantins os seus saberes e experiências construídos ao longo de suas vidas.

\section{Referências}

ARAÚJO, G.C.; OLIVEIRA, S.B.; ALMEIDA, L.S. A formação do professor de Arte em Tocantins: velhos desafios e problemas na educação brasileira. Laplage Rev., v.5, n.2, p.176-189, 2019. https://doi.org/10.24115/S2446-6220201952638p.176-189.

ARAÚJO, G.C.; OLIVEIRA, A.A. O ensino de arte na educação de jovens e adultos: uma análise a partir da experiência em Cuiabá (MT). Educ. Pesq., v.41, n.3, p.679-694, 2015a. https:// doi.org/10.1590/s1517-97022015051839.

ARAÚJO, G.C.; OLIVEIRA, A.A. Sobre o conceito de arte e a formação escolar na Educação de Jovens e Adultos. Rev. HISTEDBR, n.63, p.189-209, 2015b. doi: https://doi. org/10.20396/rho.v15i63.8641178.

ARAÚJO, G.C.; OLIVEIRA, A.A. Arte: um diálogo necessário e profícuo na Educação de jovens e adultos. EccoS, n.36, p.129142, 2015c. doi: https://doi.org/10.5585/eccos.n36.4019.

BARBOSA, A.M. O dilema das artes no ensino médio no Brasil. Pós: Rev. Prog. Pós-Grad. Artes, v.7, n.13, p.9-16, 2017a.

BARBOSA, A.M. Artes no ensino médio e transferência de cognição. Olh@res, v.5, n.2, p.77-89, 2017b. https://doi. org/10.34024/olhares.2017.v5.746.

BARBOSA, A.M. Educação sem arte, educação para a obediência. Entrevista concedida ao Jornal Extra-Classe, v.22, n.219, 2017c.

BARBOSA, A.M. A imagem no ensino da arte: anos 1980 e novos tempos. São Paulo: Perspectiva, 2012.

BARBOSA, A. M. Arte-Educação no Brasil. São Paulo: Perspectiva, 2010.

BARBOSA, A.M. Inquietações e mudanças no ensino da arte. São Paulo: Cortez, 2008.

BARBOSA, A.M. Tópicos Utópicos. Belo Horizonte: C/Arte, 1998.

BARBOSA, A.M. (Org.). O ensino da arte e sua história. São Paulo: MAC, 1990.

BOGDAN, R.; BIKLEN, S. Investigação qualitativa em educação. São Paulo: Atlas, 2010.

BRASIL. Ministério da Educação. Proposta Curricular Para a Educação de Jovens e Adultos: Segundo Segmento - Artes. Brasília: MEC, 2002.

COSTA, A.A.F.; EVANGELISTA, F. Reflexões sobre ser jovem na Educação de Jovens e Adultos no Brasil. Crítica Educ., v.3, n.3, p.56-65, 2017. doi: https://doi.org/10.22476/revcted.v3i3.285.

CURY, C.R.J. Direito à educação: direito à igualdade, direito à diferença. Cad. Pesq., n.116, p.245-262, 2002. doi: https://doi. org/10.1590/S0100-15742002000200010.

DI PIERRO, M.C. Notas Sobre a Redefinição da Identidade e das Políticas de Educação de Jovens e Adultos no Brasil. Educ.
Soc., v.26, n.92, p.1115-1139, 2005. doi: https://doi.org/10.1590/ S0101-73302005000300018.

ERICKSON, F. Qualitative methods in research on teaching. Michigan: The Institute for Research on Teaching, 1985.

FONSECA, J. J. S. Metodologia da pesquisa cientifica. Fortaleza: UEC, 2002.

HADDAD, S.; DI PIERRO, M.C. Escolarização de Jovens e Adultos. São Paulo em Perspectiva, n.14, p.108-194, 2000. doi: https://doi.org/10.1590/S0102-88392000000100005.

LAGARES, R.; BRITO, K.C.F.; SILVA, M.L.A. Gestão da educação em sistemas municipais de ensino no Tocantins: tensionamento entre princípio e método democráticos. Rev. Bras. Politica Adm. Educ., v. 36, n. 1, 2020. doi: https://doi. org/10.21573/vol36n12020.96280.

LAGARES, R. Políticas Públicas Educacionais no Tocantins (2019-2022): para onde caminha o sistema Estadual. In: ADRÃO, T. (Org.). Políticas e Prioridades para Educação Básica dos Governos Eleitos em 2018: para onde os sistemas estaduais caminham. Brasília: ANPAE, 2019. p.62-79.

LIBÂNEO, J.C. O sistema de organização e gestão da escola. In: LIBÂNEO, J.C. (Org.). Organização e gestão da escola-teoria e prática. Goiânia: Alternativa, 2001.

MACHADO, M.M. A educação de jovens e adultos: após 20 vinte anos da Lei no 9.394, de 1996. Rev. Retratos Esc., v.10, n.19. 2016. doi: https://doi.org/10.22420/rde.v10i19.687.

PAIVA, J.; HADDAD, S.; SOARES, L.J.G. Pesquisa em educação de jovens e adultos: memórias e ações na constituição do direito à educação para todos. Rev. Bras. Educ., v. 24, 2019. doi: https://doi.org/10.1590/s1413-24782019240050.

OLIVEIRA, L.G.; ARAÚJO, G.C. Arte, currículo e formação de professores: o ensino de arte nos documentos oficiais da EJA em Tocantins. In: PEREIRA, F.A.; ARAÚJO, G.C.; SILVA, S.B. Educação de Jovens, Adultos e Idosos: reflexões e experiências formativas. Veranópolis: Diálogo Freiriano, 2020. p. 67-82.

SANCEVERINO, A.R.; RIBEIRO, I.; LAFFIN, M.H.L. Estado do conhecimento das pesquisas sobre aprendizagem de pessoas jovens e adultas no campo da EJA. Perspectiva, v.38, n.1, p.1-24, 2020. doi: https://doi.org/10.5007/2175-795X.2020.e65981.

TOCANTINS. Lei $\mathrm{n}^{\mathrm{o}} 2.977$, de 8 de julho de 2015. Aprova o Plano Estadual de Educação do Tocantins - PEE/TO (2015-2025), e adota outras providências. Palmas: Diário Oficial do Estado do Tocantins, 2015.

TOCANTINS. Resolução no 024, de 14 de março de 2019. Aprova o documento curricular da educação infantil e do ensino fundamental, para o Território do Tocantins. Palmas, TO, 2019.

TOCANTINS. Estrutura Curricular para os anos iniciais do Ensino Fundamental. Palmas: SEDUC, 2016a.

TOCANTINS. Estrutura Curricular para os anos finais do Ensino Fundamental. Palmas: SEDUC, 2016 b.

TOCANTINS. Estrutura Curricular da rede Estadual de Ensino do Estado do Tocantins (Resolução n. 160, de 19 de dezembro de 2016). Palmas: SEDUC, 2016 c.

TOCANTINS. Regimento Escolar da Rede Estadual de Ensino do Estado do Tocantins. Palmas: SEDUC, 2016d. 